\title{
Novos olhares sobre o Cristianismo Primitivo
}

\author{
New looks about the Early Christianity
}

\section{Nuevas miradas sobre el Cristianismo Primitivo}

\author{
Marcelo da Silva Carneiro*
}

\section{NOGUEIRA, P. Narrativa e Cultura Popular no Cristianismo Primitivo.}

São Paulo: Paulus, 2018. 152p. Coleção Academia Bíblica.

O livro de Paulo Augusto de Souza Nogueira, "Narrativa e Cultura Popular no Cristianismo Primitivo" é, nas palavras do próprio autor, "um convite para entrar no mundo dos primeiros cristãos por meio de um exercício de estranhamento" (NOGUEIRA, 2018, p. 15). Desta afirmação e ponto de partida é que intitulamos a presente resenha, pois ele nos leva a um olhar diferenciado sobre o cristianismo primitivo (CP). Em grande parte, este olhar está fincado no trabalho de vários anos de Nogueira frente ao Grupo Oracula da Universidade Metodista de São Paulo, que tem produzido diversos trabalhos, seja em artigos, comunicações em eventos ou mesmo outros livros, sempre tendo como pano de fundo o CP, em suas diferentes manifestações. A pesquisa do Grupo Oracula não se detém aos escritos canônicos, nem às abordagens clássicas da academia, cujo parâmetro é o método históricocrítico. Nogueira tem introduzido, ao longo dos anos, diferentes abordagens aos textos, buscando novas formas de leitura e acesso ao mundo literário do cristianismo primitivo, como a hermenêutica da recepção, a partir de Bakhtin e Lótman (NOGUEIRA, 2012), a cultura visual como meio de compreender as imagens descritas nos textos, baseado em Morgan e O'Kane (NOGUEIRA, 2011) e a semiótica da cultura, importante teoria de Iuri Lótman que trata

* Doutor em Ciências da Religião pela UMESP. Email: pastor.carneiro@gmail.com 
da semiosfera (NOGUEIRA, 2015). Aliás, fica perceptível ao longo do texto, escrito com clareza e objetividade, que o autor se mantém firme no distanciamento das abordagens histórico-críticas clássicas, em favor de novas propostas e ideias.

Uma das ideias que vêm ganhando corpo na pesquisa de Nogueira é a busca de novas leituras sobre os textos denominados apócrifos, ou de elementos da cultura material dos cristãos primitivos, que podem ampliar nosso conhecimento sobre aquele período e os grupos que produziram todo esse material. Neste livro, por exemplo, Nogueira privilegia textos dos Atos Apostólicos Apócrifos como base de sua análise.

A estrutura do livro está organizada em duas partes bem definidas. Na primeira, constituída pelos capítulos 1 e 2, Nogueira faz delimitações teórico-metodológicas a respeito do CP. Ele reconhece a complexidade do tema, por isso mesmo precisa revisitar um pouco a história da pesquisa sobre o cristianismo em suas diferentes abordagens. Na segunda, composta pelos capítulos 3 a 5, o autor faz incursões narrativas, tendo como fonte alguns dos Atos Apostólicos Apócrifos, onde o olhar está submetido a teorias que analisam as fontes de modo amplo e atentos ao mundo para além do texto. A seguir apresentaremos os capítulos e suas especificidades.

O capítulo 1, "Cristianismo Primitivo? Definições, delimitações cronológicas e exploração das fontes", é o mais teórico de todo o texto, mas não menos instigante. Inicialmente Nogueira explica duas grandes tendências da pesquisa sobre o cristianismo primitivo: uma que entende que o CP é equivalente à história do Novo Testamento, e uma segunda que entende a impossibilidade de reconstruir o CP por causa da insuficiência de evidências materiais robustas e fonte extra-bíblicas. Daí em diante o autor coloca a história cultural como uma das formas de abordagem que podem ajudar a entender o CP. Antes, porém ele entende que é necessário definir o que é o cristianismo primitivo. Esse conceito passa por diversas possibilidades, dependendo de quem pesquisa e qual fonte utiliza, o que torna a definição bastante problemática.

Por isso, Nogueira define o cristianismo primitivo como um sistema de linguagem que tem como ponto de partida o movimento liderado por Jesus de Nazaré, partindo da Galileia em diferentes frentes, especialmente a partir dos anos 40 do primeiro século. Essa amplitude alcança cada vez mais territórios, superando sua origem judaica e se firmando em diversas regiões do império romano, inclusive na própria Roma. Daí Nogueira afirmar que “a rapidez e 
a eficiência com o que o cristianismo se insere no mundo mediterrâneo e a agilidade com que ele promove diálogo cultural nos mostram que essa nova religião se apresenta como comunidade de culto que se articula como um sistema de linguagem" (NOGUEIRA, 2018, p. 34, grifo do autor). A linguagem específica do cristianismo se apresenta em sua literatura própria, bem como nos temas específicos que ele privilegia. Como literatura, Nogueira entende que devemos ter no horizonte os escritos canônicos do Novo Testamento, os escritos dos Pais Apostólicos, os textos apócrifos do Novo Testamento e as Atas dos Mártires. Do ponto de vista do sistema de linguagem, essa rede textual é a base para uma ampla visão do que foi o cristianismo primitivo. Além disso, a perspectiva histórico-cultural permite ainda perceber dois aspectos a serem levados em conta: o estudo do CP por meio dos gêneros literários narrativos e imaginativos, como forma de decodificar o mundo a partir de sua fé, além da adoção de uma cronologia longa, posto que permitiria acolher muito mais material. Desse modo, Nogueira entende que se deve pensar a datação do CP até "a data limite de 313 d.C., com o Edito de Milão, do Imperador Constantino, no qual ele torna o cristianismo uma religião reconhecida pelo poder imperial, isentando-o de condenação jurídica e de ameaças de perseguição" (NOGUEIRA, 2018, p. 39).

Feito isso, Nogueira expõe as categorias que devem ser consideradas, pensando numa historicidade não factual, mas harmonizada com o conceito de sistema de linguagem. Vem daí os pontos de controle dos textos, que permitirão análises amplas e que expressem a identidade das pessoas que faziam parte desse grupo: categorias relacionadas à cultura, como tempo, espaço, sexualidade, corpo, identidade, etc.; e categorias mais específicas do grupo, especialmente em relação ao fenômeno religioso que vivenciavam.

No capítulo 2, "O cristianismo primitivo como religião popular do Mediterrâneo”, Nogueira continua sua trajetória teórica, agora com o objetivo de "mapear o registro sociocultural onde as transformações religiosas mais importantes ocorriam: a cultura popular do Mediterrâneo" (NOGUEIRA, 2018, p. 49). A primeira constatação que os estudos apontam é que havia uma ampla desigualdade do império romano, onde pouquíssimas pessoas realmente tinham acesso às camadas superiores da sociedade, por critérios bem diferentes da sociedade atual. Em geral a historiografia privilegiava esta concentração de poder, criando uma imagem da sociedade a partir da elite e não da grande massa que compunha o império, entre livres e escravos. 
Para Paulo Nogueira, o cristianismo primitivo estaria muito mais próximo das camadas populares do que da elite, ainda que tenha usado largamente o recurso da escrita, condição associada à elite intelectual e do poder. Isso se deve pela natureza dos textos, das narrativas e dos gêneros literários utilizados pelos cristãos. Em grande parte, são gêneros híbridos, que emulam a literatura greco-romana com outra roupagem, própria para identificar o grupo. Desse modo, é possível afirmar que os cristãos faziam parte de uma religião originada nos grupos subalternos, e por isso seria uma religião popular no Mediterrâneo, o que faz com que Nogueira identifique algumas características da cultura popular no contexto do Mediterrâneo, sendo quatro apontadas no texto: não há coerência nem sistematização, tem ampla circulação, também é um espaço de disputa de poder e coexiste com a retórica de exclusividade dos grupos religiosos.

Tendo esse pressuposto como parâmetro, Nogueira estabelece três eixos de análise, a partir dos quais irá ler os textos: as práticas mágicas dos grupos subalternos, evidenciadas por amuletos, fórmulas mágicas e outras testemunhas materiais; o espaço das relações domésticas, espaço social por excelência no mundo greco-romano, onde disputas de poder e o funcionamento das relações é evidenciado ou invertido; os modos de narrar, que indicam origem na oralidade no ambiente folclórico para os textos, em especial os que posteriormente foram considerados apócrifos.

Nogueira então faz um grande resumo metodológico, que irá embasar a análise dos textos que serão descortinados nos capítulos seguintes, tendo em mente uma ampla compreensão do que era o cristianismo primitivo, mesmo que localizado na cultura popular do Mediterrâneo. Para isso, ele propõe uma abordagem comparativa de diferentes fontes e também artefatos ligados a este mundo social. Para uma aplicação prática, portanto, ele toma os Atos Apócrifos como fonte de análise.

A partir do capítulo 3 e seguintes, Nogueira aplica suas teorias de análise aos textos indicados, buscando em cada um aspectos próprios que marcam essas obras. O capítulo 3, "Os Atos Apócrifos e religiosidade popular no Mediterrâneo: Temas e narrativas folclóricas nos Atos de Paulo", faz uma introdução ao gênero dos Atos Apócrifos, explicando o lugar deles no CP. Também indica como a academia em geral despreza esse material, como se não pudesse fornecer informações válidas sobre os cristãos nas origens, pelo fato de não serem tão antigos. Nogueira se afasta dessa tendência, justamente por considerar a longa cronologia. Ainda neste capítulo, ele passa a falar das 
reconstruções da memória de Paulo a partir de Atos de Paulo e Tecla, e como eles formam um importante testemunho do folclore cristão, como a versão mais arrojada da passagem de Paulo por Éfeso, além das relações de gênero e suas diferentes tendências, entre o empoderamento feminino e a submissão feminina ao poder masculino.

Outro texto importante é analisado no capítulo 4, "Ações públicas poderosas e subversão da realidade: os milagres do apóstolo nos Atos Apócrifos de João". Aqui Nogueira se debruça no material que mostra as ações públicas de João em Éfeso, mostrando inclusive a destruição que ele promoveu do Artemísio, evento que dificilmente pode ter sido histórico, mas que ainda assim é reconstruído ficcionalmente sem nenhum constrangimento. Diante disso, Nogueira entende que é preciso analisar o sentido pragmático do texto, ou seja, o que ele queria provocar em seus ouvintes/leitores, mais do que a questão se é um texto histórico ou não. Nossa tendência é de só considerar válidos textos que tenham um fundo histórico aceitável, mas não era essa a lógica dos leitores daquela época. Assim que, diante desse paradoxo, o conceito de carnavalização de Mikhail Bakhtin é o que pode explicar isso. Como afirma Nogueira: "Trata-se de um modo de literatura de inversão de mundo que, como, por exemplo, a sátira menipeia, inverte relações sociais com o riso, com intervenções irreverentes e elementos do grotesco" (NOGUEIRA, 2018, p. 109).

Seguindo esta lógica carnavalesca, Nogueira analisa no capítulo 5, "Entre monstros, animais e humanos: Ambiguidades e cruzamentos de fronteiras nos Atos de Felipe", o quanto os Atos de Felipe estão próximos do monstruoso e do grotesco. Ele entende que é uma narrativa plena de ambiguidades e cruzamentos de fronteira, entre animal-humano, humanomonstruoso, dentre outros elementos paradoxais. Aqui o autor descreve literariamente a obra com mais detalhes que as anteriores, o que facilita o leitor em sua contextualização, ainda que Nogueira afirme ser um "enredo labiríntico" (NOGUEIRA, 2018, p. 134). Apesar disso, Nogueira consegue perceber uma estrutura quiástica no texto, cujo centro é o deserto, lugar onde Felipe enfrenta um grande dragão. Há no texto animais que falam (como também no relato de Paulo em Éfeso), e entrevistas do apóstolo com os demônios, com o fim de compreender sua natureza e missão, para então os expulsar. Até mesmo Felipe e sua irmão Mariane enfrentam paradoxos e cruzamentos de fronteira, entre o feminino e o masculino. 
Ao fim da obra, o próprio autor reconhece que não fez uma aplicação muito ampla, mas que dadas as condições, o universo das fontes permite que estas análises tenham uma aplicação universal. Com isso ele faz uma conclusão que reúne os principais aspectos levantados nas análises das narrativas, mediante os fundamentos metodológicos anunciados. Ainda assim, ficou a sensação de que poderia ter explorado outras obras, ou ainda, estabelecido outros recortes. A questão da magia, por exemplo, é apenas apontada, mas não foi aprofundada nas análises, ainda que tenha sido considerada nos Atos de Paulo e Tecla.

Podemos afirmar que o livro é, no fim das contas, uma excelente amostra da nova pesquisa sobre o cristianismo primitivo, com texto acessível mesmo aos que não são da área, ou não são pós-graduados. Certamente irá instigar novos leitores a esse universo, que ainda tem muito a ser explorado, considerando as diferentes teses e dissertações sobre o tema elaborados no programa de pós-graduação da Metodista. Para os pesquisadores brasileiros também servirá como ponto de apoio para introduzir novas abordagens aos textos, inclusive aos canônicos, tendo por base um olhar não dogmático, seja no sentido religioso ou acadêmico. Sem desconsiderar o quanto Nogueira é devedor de pesquisadores da América do Norte e da Europa, é possível afirmar que, da forma como as teorias estão elaboradas e as análises aplicadas aos textos, é uma obra que certamente contribuirá com a pesquisa em âmbito internacional.

\section{Referências}

NOGUEIRA, P. A. de S. Do silêncio do texto às imagens da ressurreição: cultura visual e interpretação bíblica. Revista Pistis \& Praxis. Teologia e Pastoral. V.3, n.1, p. 221-237, jan./ jun. 2011.

Hermenêutica da Recepção: Textos bíblicos nas fronteiras da cultura e no longo tempo. Estudos da Religião. V. 26, n. 42, jan.-jun. 2012.

Traduções do Intraduzível: a semiótica da cultura e o estudo de textos religiosos nas bordas da semiosfera. Estudos da Religião. V. 29, n. 1, p. 102-123, jan.-jun. 2015.

Submetida em: 23-1-2019

Aceita em: 28-4-2019 